\title{
Human Recombinant Granulocyte-Macrophage Colony-stimulating Factor Increases Cell-to-Cell Adhesion and Surface Expression of Adhesion-promoting Surface Glycoproteins on Mature Granulocytes
}

\author{
M. A. Arnaout, * E. A. Wang,\$ S. C. Clark,\$ and C. A. Sieff¥ \\ *Division of Nephrology, Department of Medicine, The Childrens Hospital; $\ddagger$ Division of Pediatric Oncology, Dana Farber Cancer \\ Institute, Boston, Massachusetts 02115; and \$the Genetics Institute, Cambridge, Massachusetts 02140
}

\begin{abstract}
Human granulocyte-macrophage colony-stimulating factor (GMCSF) has been shown to inhibit migration of mature granulocytes and to enhance their antibody-dependent cellular cytotoxicity. We found that human recombinant GM-CSF also enhanced granulocyte-granulocyte adhesion and increased by two- to threefold the surface expression of Mol and LeuM5 (P150, 95), two members of a family of leukocyte adhesion molecules (LeuCAM). Increased Mo1 surface expression occurred within 15 min at $37^{\circ} \mathrm{C}$ and was maximal at the migration inhibitory concentration of 500 pM. One-half maximal rise in the expression of Mol on the cell surface occurred at $5 \mathrm{pM}$. The chemotactic peptide $f$-Met-Leu-Phe produced a comparable rise in surface Mo1 with one-half maximal expression occurring at $7 \mathrm{nM}$. Both GM-CSF and $f$-Met-Leu-Phe produced optimal granulocytegranulocyte adhesion at $500 \mathrm{pM}$ and $100 \mathrm{nM}$, respectively. This adhesion-promoting effect induced by either stimulus was inhibited by a mouse monoclonal antibody directed against Mo1 antigen. These data indicate that GM-CSF promotes cell-to-cell adhesion, presumably through enhanced expression of leukocyte adhesion molecules. This mechanism may explain, in part, the known effects of GM-CSF on the function of mature granulocytes.
\end{abstract}

\section{Introduction}

Human granulocyte-macrophage colony-stimulating factor $(\mathrm{GM}-\mathrm{CSF})^{1}$ is a glycoprotein produced by mitogen- or antigenstimulated lymphocytes (1). The sequences encoding both human- and mouse-derived GM-CSF have recently been cloned, greatly facilitating the production of substantial quantities of the pure proteins. Human GM-CSF has been expressed in mammalian cells. The recombinant product $(2,3)$ migrates on sodium

Address reprint requests to Dr. Arnaout, Renal Division, The Children's Hospital, Boston, MA 02115.

Received for publication 2 April 1986.

1. Abbreviation used in this paper: GM-CSF, granulocyte-macrophage colony-stimulating factor.

J. Clin. Invest.

(c) The American Society for Clinical Investigation, Inc.

0021-9738/86/08/0597/05 \$1.00

Volume 78, August 1986, 597-601 dodecyl sulphate-polyacrylamide gel electrophoresis as a broad band, ranging in molecular mass between 18 and $35 \mathrm{kD}$ (due to variable glycosylation) with the major glycoprotein at $22 \mathrm{kD}$ $(2,3)$. The availability of the pure recombinant CSF has greatly facilitated the analysis of its biological properties both in vitro (4-9) and in vivo. (Donohue, R. E., E. A. Wang, D. Stone, R. Kamen, G. G. Wong, P. K. Sehgal, D. G. Nathan, and S. C. Clark, manuscript submitted for publication). These studies have demonstrated that in addition to its ability to induce proliferation and differentiation of several classes of bone marrow progenitor cells (4), it has a number of effects on mature granulocyte function, such as inhibition of migration, enhancement of antibodydependent cell-mediated cytotoxicity, and enhanced superoxide anion production in response to $f$-Met-Leu-Phe $(9,10)$ (Donohue, R. E., E. A. Wang, D. Stone, R. Kamen, G. G. Wong, P. K. Sehgal, D. G. Nathan, and S. C. Clark, manuscript submitted for publication). Recently, a family of leukocyte adhesion molecules (Leu-CAM) consisting of three surface antigens known as Mo1, LFA-1, and LeuM5 (P150, 95) were identified using monoclonal antibodies (11-13). Each molecule consists of a distinct alpha subunit noncovalently linked to an identical beta subunit (11-13). Inherited deficiency of this family of molecules is associated with impairment in granulocyte adhesion-dependent functions such as chemotaxis, leukoaggregation, antibodydependent cell-mediated cytotoxicity, and complement receptor type 3 (14). In this study we investigated the possibility that some of the effects of GM-CSF on mature granulocytes may be secondary to enhanced cell adhesion mediated by increased surface expression of one or more members of the Leu-CAM family.

\section{Methods}

Recombinant GM-CSF was produced in Chinese hamster ovary cells (to be published elsewhere) and purified to homogeneity using reverse-phase high performance liquid chromatography as previously described $(2,3)$. The undiluted material contained $<0.2 \mathrm{ng}$ of endotoxin $/ \mathrm{ml}$, as determined by a Limulus amoebocyte lysate assay kit (M.A. Bioproducts, Walkersville, MD). Dilutions from the stock were made in Dulbecco's modified Eagle's medium (Gibco, Grand Island, NY) containing $0.5 \%$ bovine serum albumin and kept frozen at $-70^{\circ} \mathrm{C}$ until use.

The chemotactic peptide $f$-Met-Leu-Phe and lipopolysaccharide B (Escherichia coli 026:B6) were obtained from Sigma Chemical Co., St. Louis, MO and Difco Laboratories, Inc., Detroit, MI, respectively. Medium RPMI 1640, human serum albumin, and Linbro-96 round bottom microtiter plates were purchased from M.A. Bioproducts, Alpha Therapeutic Corp., Los Angeles, CA, and Flow Laboratories, Inc., McLean, VA, respectively. 
Mouse monoclonal antibodies directed against Mo1, LFA-1, LeuM5 (P150,95), and their common beta subunit were kindly provided respectively by Drs. R. F. Todd III (Ann Arbor, MI) (15), Hergen Spits (University of Amsterdam) (16), Louis Lanier (Becton-Dickinson \& Co., Mountain View, CA) (17), and Sam Wright (The Rockefeller University, New York) (13). The Fab fragment of monoclonal antibodies directed against Mol or Mo5, another granulocyte surface antigen (18), was generated as described (19).

Human granulocytes were purified at $4^{\circ} \mathrm{C}$ from EDTA-anticoagulated blood by Ficol-Hypaque centrifugation followed by hypotonic lysis of contaminating red blood cells as previously described (20).

Immunofluorescence analysis. After incubation with medium, GMCSF, or $f$-Met-Leu-Phe, granulocytes were washed, incubated with saturating amounts of the monoclonal antibodies $\left(30 \mathrm{~min}, 4^{\circ} \mathrm{C}\right)$, washed, and then incubated with fluorescein-labeled goat anti-mouse Ig (Meloy Laboratories, Inc., Springfield, VA) for $30 \mathrm{~min}$ at $4^{\circ} \mathrm{C}$. The washed cells were then fixed with $1 \%$ formaldehyde and fluorescence-measured on a FACS IV fluorocytometer (Becton-Dickinson \& Co., FACS Division, Sunnyvale, CA). The analysis was displayed as single parameter histograms with the $x$-axis representing relative fluorescence intensity (log scale, 256 channels, 48 channels/log decade) and the $y$-axis representing cell number. Fluorescence measurements were converted from a logarithmic to a linear scale using a calibration factor.

Leukoaggregation assays. Enhanced cell-to-cell adhesion in response to f-Met-Leu-Phe or GM-CSF was measured using two different assays. (a) The microtiter plate assay was performed as previously described (21). Briefly, to $50 \mu \mathrm{l}$ of granulocytes $\left(8 \times 10^{6} / \mathrm{ml}\right.$ in isotonic Tris- $\mathrm{NaCl}$, $\mathrm{pH}$ 7.4) various concentrations of $f$-Met-Leu-Phe or GM-CSF were added. The final volume was brought to $400 \mu l$ with RPMI 1640 medium containing $0.1 \%$ human serum albumin. Cells were rapidly resuspended and $200-\mu$ l aliquots were placed in duplicate wells in a 96-round bottom microtiter plate. After a 25 -min incubation at $37^{\circ} \mathrm{C}$ in a humidified atmosphere containing 5\% $\mathrm{CO} 2$, the cell settling patterns were assessed by visual inspection. Untreated cells settled to a round pellet at the center of the well (0 aggregation). Aggregated cells settled in a diffuse manner covering the bottom of the well (1+-4+ aggregation). In each case aggregation was confirmed by removing an aliquot of cells obtained from replicate wells, fixing the cells in $1 \%$ formaldehyde, and then determining their aggregation status by phase microscopic examination. The effect of an anti-Mol monoclonal antibody on leukoaggregation was tested by including the Fab fragment of anti-Mol (or the control anti-Mo5 monoclonal antibody) in the reaction mixture (at $15 \mu \mathrm{g} / \mathrm{ml}$ ) before addition of the aggregant.

(b) Granulocyte aggregation was also measured nephelometrically using a platelet aggregometer (model $300 \mathrm{BD}$; Payton Associates, Buffalo, NY) as previously described (22). Aggregation in response to $f$-Met-LeuPhe $\left(10^{-6} \mathrm{M}\right)$ or GM-CSF $\left(2 \times 10^{-9} \mathrm{M}\right)$ was recorded as an increment in light transmission $(\Delta \mathrm{T})$ on an arbitrary scale. Calibration was based on a granulocyte suspension diluted by $25 \%$.

\section{Results}

Increase of Mol and LeuM5 $(P 150,95)$ surface expression on mature granulocytes by GM-CSF. Granulocytes incubated with GM-CSF $\left(10 \mathrm{ng} / \mathrm{ml}, 5 \times 10^{-10} \mathrm{M}\right)$ for $15 \mathrm{~min}$ at $37^{\circ} \mathrm{C}$ increased their surface expression of Mol and LeuM5 $(\mathrm{P} 150,95)$ as well as their common beta subunit by 2.8 -fold, 2.0 -fold, and 2.3-fold, respectively (Fig. 1). No significant rise in the surface expression of LFA-1 was detected. The increased expression of Mol (both alpha and beta subunits) was rapid, reaching $\sim 85 \%$ of the maximal response within $5 \mathrm{~min}$ at $37^{\circ} \mathrm{C}$ (not shown). One-half maximal increase in Mol surface expression occurred at a GM-CSF concentration of $5 \times 10^{-12} \mathrm{M}$ with maximal expression reached at $5 \times 10^{-10} \mathrm{M}$ (Fig. 2). This latter GM-CSF concentration maximally inhibited granulocyte migration by $33 \%$ (Wang, E. A.

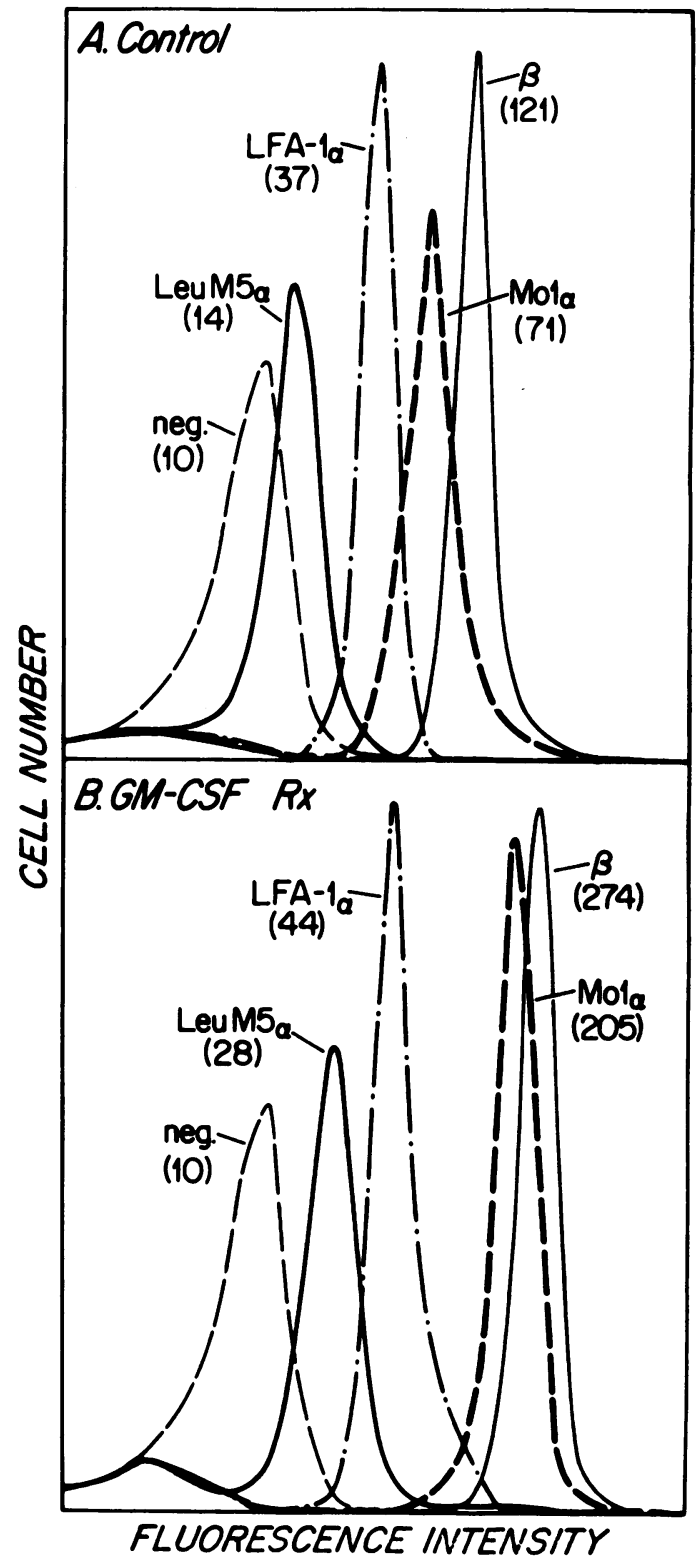

Figure 1. Effect of GM-CSF $\left(5 \times 10^{-10} \mathrm{M}\right)$ on the surface expression of the alpha subunits of Mol $\left(\mathrm{Mol}_{\alpha}\right)$, LFA-1 (LFA-1 $\left.{ }_{\alpha}\right)$, LeuM5 (LeuM5 $5_{\alpha}$ ), and their common beta subunit $(\beta)$. Quantitative expression of these antigens on cells treated with medium alone $(A)$ or $\mathrm{GM}$ CSF $(B)$ was performed using a FACS IV flow cytometer. The mean peak channel fluorescence was converted into a linear value, as indicated in parentheses. GM-CSF-induced rise in surface expression (compared with medium alone) of Mo1, LFA-1, and LeuM5 was: (Mean \pm SD) $2.4 \pm 0.36$-fold, $1.125 \pm 0.15$-fold, and 2.05 \pm 0.68 -fold $(n=4)$, respectively.

and S. C. Clark, unpublished observations). In comparison, $f$ Met-Leu-Phe induced one-half maximal Mol expression at 7 $\times 10^{-9} \mathrm{M}$ (Fig. 2). At $1 \times 10^{-6} \mathrm{M}$, an $\mathrm{f}$-Met-Leu-Phe concentration that inhibited chemotaxis (23), Mol surface expression was maximal (2.6-fold \pm 0.37 , mean $\pm \mathrm{SD}, n=5)$ and comparable to that induced by GM-CSF at $5 \times 10^{-10} \mathrm{M}(2.4$-fold \pm 0.36 , mean $\pm S D, n=4)$. The effects of GM-CSF on Mol surface expression were not produced by lipopolysaccharide $B$ in concentrations between 1 and $50 \mu \mathrm{g} / \mathrm{ml}$. (data not shown). 


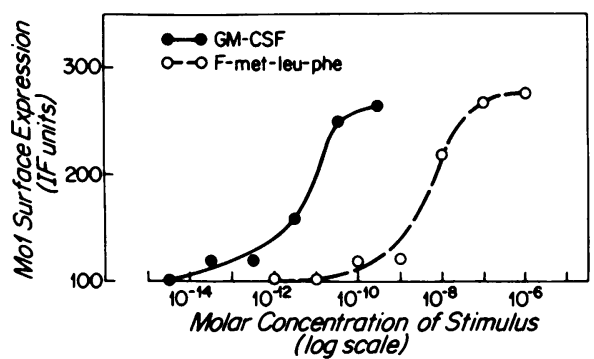

Figure 2. Dose-response curves showing the effects of varying concentrations of GM-CSF or $f$-Met-Leu-Phe on the surface expression of Mol on granulocytes. Mol expression of cells exposed to medium for $15 \mathrm{~min}$ at $37^{\circ} \mathrm{C}$ were arbitrarily assigned a value of 100 immunofluorescence units (IF). Points represent the mean of two independent experiments. Maximal expression of Mol was induced by GM-CSF at a molar concentration that is $\sim 1000$-fold lower than the concentration of $f$-Met-Leu-Phe required to produce a similar effect.

Enhancement of granulocyte-granulocyte adhesion (leukoaggregation) by GM-CSF. As shown in Fig. 3, granulocytes aggregated (as reflected by an increase in light transmission) when exposed to GM-CSF $\left(2 \times 10^{-9} \mathrm{M}\right)$ (tracing $\left.A\right)$ or to $f$-Met-LeuPhe $\left(10^{-6} \mathrm{M}\right)$ (tracing $C$ ). The effect of medium used to dilute GM-CSF (tracing $B$ ) was not significantly different from buffer alone (tracing $D$ ). Since changes in light transmission not only reflect aggregation but also changes in cell shape (24), a more direct microtiter plate assay was also used to measure aggregation. As shown in Fig. 4 (top), untreated granulocytes did not aggregate and settled to a spot at the center of the well (well $a$ ). Granulocytes treated with GM-CSF $\left(5 \times 10^{-10} \mathrm{M}\right)$ (well $\left.c\right)$ or $f$-Met-Leu-Phe $\left(10^{-6} \mathrm{M}\right)$ (well $b$ ) aggregated and settled in a diffuse manner uniformly covering the base of the wells (4+ aggregation). Leukoaggregation was confirmed by microscopic examination of a cell aliquot from replicate wells treated with medium alone or

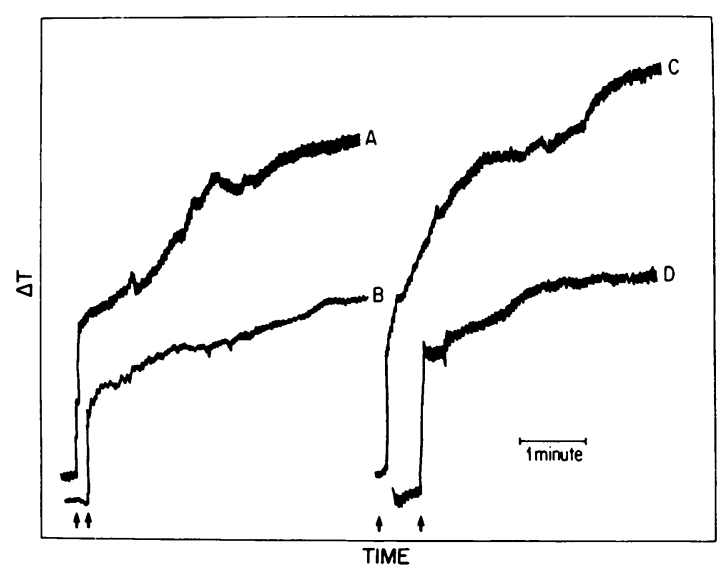

Figure 3. Effect of GM-CSF $\left(2 \times 10^{-9} \mathrm{M}\right)$ and $f$-Met-Leu-Phe $\left(10^{-6}\right.$ $M)$ on granulocyte aggregation. Leukoaggregation was recorded as an increase in light transmission $(\Delta \mathrm{T}, y$-axis) over the time in minutes $(x$ axis). Tracings $A$ and $C$ show the aggregation responses to GM-CSF and $f$-Met-Leu-Phe, respectively. The addition of buffer (tracing $D$ ) or medium (tracing $B$ ) to granulocytes resulted in a dilution artifact with no significant aggregation responses. Arrows indicate the point in time at which stimulus or buffer was added to the cell suspension. Similar results were obtained in two additional experiments. with GM-CSF. Cells treated with medium alone did not aggregate (Fig. 4, bottom, panel 1). GM-CSF-treated $\left(5 \times 10^{-10} \mathrm{M}\right)$ cells, however, formed large aggregates (Fig. 4, bottom, panel 2). $f$ Met-Leu-Phe produced one-half maximal aggregation $(2+)$ in the microtiter assay at $10^{-8} \mathrm{M}$ while GM-CSF produced a similar response at $10^{-11} \mathrm{M}$ (not shown). Significantly, aggregation induced by GM-CSF or $f$-Met-Leu-Phe was inhibited by the Fab fragment of a monoclonal antibody to Mol (Fig. 4, top, wells $f$ and $g$, respectively) but not by a control antibody directed against Mo5, another granulocyte surface antigen (Fig. 4, top, wells $d$ and $e$ ).

\section{Discussion}

In this study, recombinant GM-CSF rapidly increased the expression of Mol and LeuM5 antigens on the surface of mature granulocytes and enhanced adhesion of granulocytes to each other. Cell-to-cell adhesion was blocked by the Fab fragment of an anti-Mol monoclonal antibody, suggesting that the Mol antigen is involved in this GM-CSF-induced function. GM-CSF is thus similar to a number of stimuli, such as $f$-Met-Leu-Phe, phorbol esters, complement C5a, calcium ionophore A23187, and tumor necrosis factor (25-27) that increase expression of $\mathrm{Mol}$ on the surface membrane of granulocytes. Increased Mol surface expression induced by these stimuli occurs within minutes and may be due, as in the case of calcium ionophore A23187, to a translocation of $\mathrm{Mol}$ from an intracellular pool present in the secondary and/or tertiary granules to the cell surface $(25$, 28 ). Although both GM-CSF and $f$-Met-Leu-Phe induced comparable amounts of surface Mol expression (Fig. 2), GM-CSF was approximately 1,000 times more potent than $f$-Met-LeuPhe, on a molar basis. This significant difference was also seen in the granulocyte aggregation response (Figs. 3 and 4). Onehalf maximal stimulation of Mol surface expression and of aggregation occurred at 5-10 pM (Fig. 2 and data not shown), in agreement with the recently derived binding affinity of ${ }^{125} \mathrm{I}-\mathrm{GM}$ CSF to neutrophils (dissociation constant, $17 \mathrm{nM}$ ) (29).

It has previously been established that $f$-Met-Leu-Phe is chemotactic to human granulocytes at concentrations below $10^{-8}$ $M$. At higher concentrations $\left(10^{-6} \mathrm{M}\right), f$-Met-Leu-Phe inhibits granulocyte migration (so-called chemotactic deactivation) (23). One possible mechanism for the latter effect appears to be increased adhesion of cells to the substratum produced by the higher concentration of the stimulus (23). It is interesting to note that in this concentration range, $f$-Met-Leu-Phe produced maximal Mol surface expression (Fig. 2) and adhesion of granulocytes to each other (Figs. 3 and 4). GM-CSF in concentrations that inhibit granulocyte migration $\left(5 \times 10^{-10} \mathrm{M}\right)$ also produced similar phenotypic and functional cell responses (Figs. 1, 2, and 3). It appears likely, therefore, that the migration inhibitory effects of GM-CSF may be mediated, in part, by enhanced cell adhesion secondary to increased surface expression of certain leukocyte adhesion molecules.

Finally, this adhesion-promoting function of GM-CSF on mature granulocytes may be important in vivo. GM-CSF produced locally may help in trapping granulocytes at the inflammatory site and in enhancing their cytotoxic functions. Systemic production of this cytokine, on the other hand, may impair vascular egress of these phagocytic cells and predispose to systemic leukoaggregation and bacterial dissemination. This may be of importance in devising protocols for using this cytokine therapeutically in humans. 


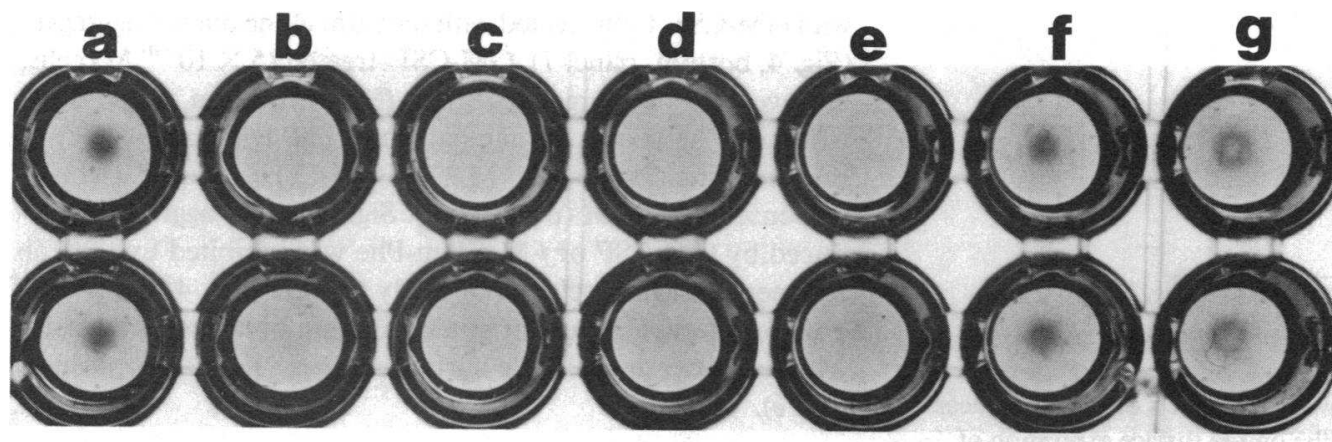

Figure 4. (Top) Effects of GM-CSF $\left(5 \times 10^{10} \mathrm{M}\right)$ and $f$ Met-Leu-Phe $\left(1 \times 10^{-6} \mathrm{M}\right)$ on granulocyte aggregation. Both GM-CSF and $f$-MetLeu-Phe caused granulocytes to aggregate and therefore settle in a diffuse manner totally covering the bottom of the microtiter well $(4+$ aggregation) (wells $c$ and $b$, respectively). Cells treated with medium alone did not aggregate and therefore settled to a round pellet at the center of
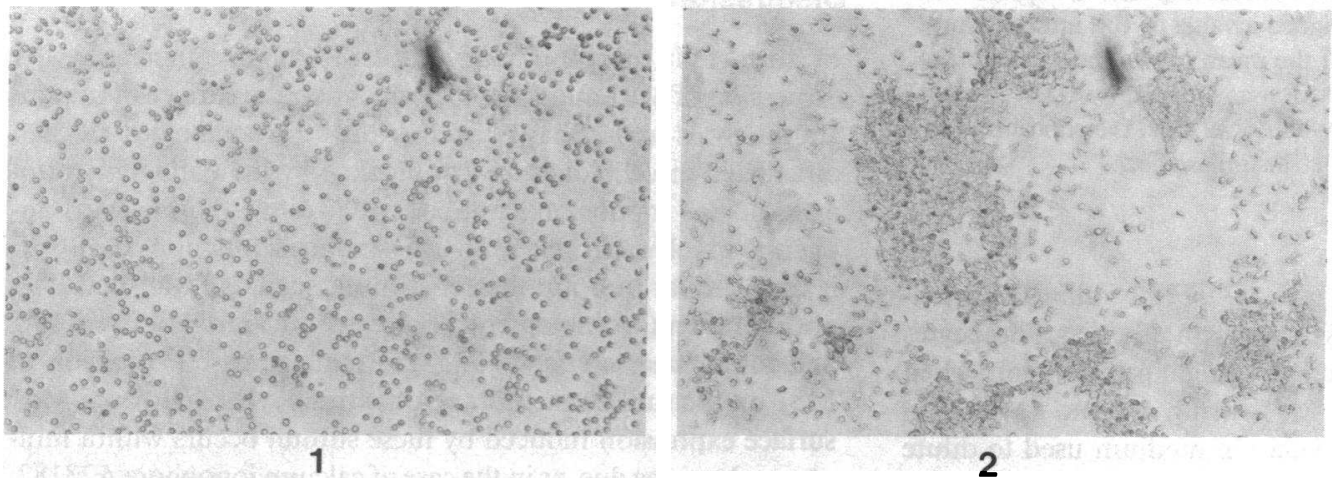
the microtiter well ( 0 aggregation) (well $a$ ). The Fab fragment of anti-Mol monoclonal antibody inhibited granulocyte aggregation when the latter was induced either by GM-CSF (well $f$ ) of $f$-MetLeu-Phe (well $g$ ). The control monoclonal antibody had no inhibitory effect (wells $d$ and $e$ ). Each assay was performed in duplicate. Similar results were obtained in four inde-

pendent experiments. (Bottom) Light microscopic examination of cells treated with medium alone (panel 1 ) or with GM-CSF $\left(5 \times 10^{-10} \mathrm{M}\right)$ (panel 2). Granulocyte aggregation was seen only in the latter. Magnification, $\times 100$.

\section{Acknowledgments}

The authors wish to thank Dr. David G. Nathan for his helpful suggestions and his critical review of the manuscript, Ms. Leslie Myers for her technical assistance, and Ms. Toni Condangelo for her secretarial help.

Dr. Arnaout was supported by US Public Health Service grant AI 21963 and by March of Dimes grant 1-1010. He is an Established Investigator of the American Heart Association.

\section{References}

1. Metcalf, D. 1986. The molecular biology and functions of the granulocyte-macrophage colony stimulating factors. Blood. 67:257-267.

2. Wong, G. G., J. S. Witek, P. A. Temple, K. M. Wilken, A. C. Leary, D. P. Luxenberg, S. S. Jones, E. L. Brown, R. M. Kay, E. C. Orr, C. Shoemaker, D. W. Golde, R. J. Kaufman, R. M. Hewick, E. A. Wang, and S. C. Clark. 1985. Human GM-CSF: molecular cloning of the complementary DNA and purification of the natural and recombinant proteins. Science (Wash. DC). 228:810-815.

3. Wong, G. G. 1985. Cancer cells 3. In Growth Factors and Transformation. J. Feramisco, B. Ozanne, and C. Stiles, editors. Cold Spring Harbor Laboratory, Cold Spring Harbor, NY. 235-242.

4. Sieff, C. A., S. G. Emerson, R. E. Donahue, D. G. Nathan, E. A. Wang, G. G. Wong, and S. C. Clark. 1985. Human granulocyte-macrophage colony stimulating factor: a multilineage hematopoietin. Science (Wash. DC). 230:1171-1173.

5. Emerson, S. G., C. A. Sieff, A. Wang, G. G. Wong, S. C. Clark, and D. G. Nathan. 1985. Purification of fetal hematopoietic progenitors and demonstration of recombinant multipotential colony-stimulating activity. J. Clin. Invest. 76:1286-1290.

6. Donahue, R. E., S. G. Emerson, E. A. Wang, G. G. Wong, S. C. Clark, and D. G. Nathan. 1985. Demonstration of burst-promoting activity of recombinant human GM-CSF on calculating erythroid progenitors using an assay involving the delayed addition of erythropoietin. Blood. 66:1479-1481.
7. Metcalf, D., C. G. Begley, G. R. Johnson, N. A. Nicola, M. A. Vadas, A. F. Lopez, D. J. Williamson, G. G. Wong, S. C. Clark, and E. A. Wang. 1986. Biologic properties in vitro of a recombinant human granulocyte-macrophage colony stimulating factor. Blood. 67:37-45.

8. Gasson, G. C., R. H. Weisbart, S. E. Kaufman, S. C. Clark, R. M. Hewick, and G. G. Wong. 1984. Purified human granulocyte-monocyte colony-stimulating factor: direct action on neutrophils. Science (Wash. DC). 226:1339-1342.

9. Vadas, M. A., N. A. Nicola, and D. Metcalf. 1983. Activation of antibody-dependent cell-mediated cytotoxicity of human neutrophils and eosinophils by separate colony stimulating factors. J. Immunol. 130: 795-799.

10. Weisbart, R. H., D. W. Gold, S. W. Clark, G. G. Wong, and J.C. Gasson. 1985. Human granulocyte-macrophage colony stimulating factor is a neutrophil activator. Nature (Lond.). 314:361-363.

11. Trowbridge, I. S., and M. B. Omary. 1981. Molecular complexity of leukocyte surface glycoproteins related to the macrophage differentiation antigen Mac-1. J. Exp. Med. 154:1517-1524.

12. Sanchez-Madrid, F., J. A. Nagy, E. Robins, P. Simon, and T. A. Springer. 1983. A human leukocyte differentiation family with distinct alpha subunits and a common beta subunit: the lymphocyte function associated antigen (LFA-1), the C3bi complement receptor (OKM 1/ Macl) and the P150, 95 molecule. J. Exp. Med. 158:1785-1803.

13. Wright, S. D., P. E. Rao, W. C. van Voorhis, L. S. Craigmyle, K. Iida, M. A. Talle, E. F. Westberg, G. Goldstein, and S. C. Silverstein. 1983. Identification of the complement $\mathrm{C} 3 \mathrm{bi}$ receptor using monoclonal antibodies. Proc. Natl. Acad. Sci. USA. 86:5699-5703.

14. Arnaout, M. A., N. Dana, J. Pitt, and R. F. Todd. 1984. Deficiency of two human leukocyte surface membrane glycoproteins (Mol and LFA1). Fed. Proc. 44:2664-2670.

15. Todd, R. F., III, A. K. Bahn, S. E. Kabawat, and S. F. Schlossman. 1984. Human myelomonocytic differentiation antigens defined by monoclonal antibodies. In Leukocyte Typing. B. A. Bounswell, J. Dausset, C. F. Milstein, and S. F. Schlossman, editors. Springer-Verlag, New York. 424-33. 
16. Keizer, G. D., J. Borst, C. G. Figdor, H. Spits, F. Miedema, C. Terhorst, and J. E. De Vreis. 1985. Biochemical and functional characteristics of the human leukocyte membrane antigen family LFA-1, Mol and p150, 95. Eur. J. Immunol. 15:1142-1148.

17. Lanier, L. L., M. A. Arnaout, R. Schwarting, N. L. Warner, and G. D. Ross. 1985. P150/95, third member of the LFA-1/CR3 polypeptide family identified by anti-Leu-M5 monoclonal antibody. Eur. J. Immunol. 15:713-718.

18. Todd, R. F., J. Roache, and M. A. Arnaout. 1985. The modulated expression of Mo5, a human myelomonocytic plasma membrane antigen. Blood. 65:964-973.

19. Parham, P. 1983. On the fragmentation of monoclonal IgG 1 , IgG 2a and IgG 2b from BALB/c mice. J. Immunol. 131:2895-2902.

20. Boyum, A. 1968. Isolation of mononuclear cells and granulocytes from human blood. Scand. J. Clin. Lab. Invest. 97:(Suppl):77-89.

21. Arnaout, M. A., M. Pierce, N. Dana, and L. Clayton. 1986. Complement receptor type 3. Methods Enzymol. In press.

22. Hammerschmidt, D. E., T. K. Bowers, C. J. Lammi-Keefe, H. S. Jacob, and P. R. Craddock. 1980. Granulocyte aggregometry: a sensitive technique for the detection of $\mathrm{C} 5 \mathrm{a}$ and complement activation. Blood. 55:898-902.

23. Fehr, J., and C. Dahinden. 1979. Modulating influence of chemotactic factor-induced cell adhesiveness on granulocyte function. $J$. Clin. Invest. 64:8-16.
24. Yuli, I., and R. Snyderman. 1984. Light scattering by polymorphonuclear leukocytes stimulated to aggregate under various pharmacologic conditions. Blood. 64:649-659.

25. Arnaout, M. A., H. Spits, C. Terhorst, J. Pitt, and R. F. Todd III. 1984. Deficiency of a leukocyte surface glycoprotein (LFA-1) in two patients with Mol deficiency: effects of cell activation on Mol/LFA-1 surface expression in normal and deficient leukocytes. J. Clin. Invest. 74:1291-1300.

26. Arnaout, M. A., R. M. Hakim, R. F. Todd III, N. Dana, and H. R. Colten. 1985. Increased expression of an adhesion promoting surface glycoprotein in the granulocytopenia of hemodialysis. N. Engl. J. Med. 312:457-462.

27. Gamble, J. R., J. M. Harlan, S. J. Klebanoff, and M. A. Vadas. 1985. Stimulation of the adherence of neutrophils to umbilical vein endothelium by human recombinant tumor necrosis factor. Proc. Natl. Acad. Sci. USA. 82:8667-8671.

28. Petrequin, P. R., R. F. Todd III, L. J. Devall, L. A. Boxer, and J. T. Curnutte. 1985. Association between tertiary granule release and increased plasma membrane expression of the Mol glycoprotein. Blood. 66(Suppl 1):91a. (Abstr.)

29. Gasson, J. C., S. E. Kaufman, R. H. Weisbart, M. Tomonaga, and D. W. Golde. 1986. High affinity binding of granulocyte-macrophage colony-stimulating factor to normal and leukemic human myeloid cells. Proc. Natl. Acad. Sci. USA. 83:669-673. 